NASA/TM-2005-213895

Description of the Prometheus Program Alternator/Thruster Integration Laboratory (ATIL)

Anastacio N. Baez, Arthur G. Birchenough, and Ramon C. Lebron-Velilla Glenn Research Center, Cleveland, Ohio

Marcelo C. Gonzalez

Cleveland State University, Cleveland, Ohio 
Since its founding, NASA has been dedicated to the advancement of aeronautics and space science. The NASA Scientific and Technical Information (STI) Program Office plays a key part in helping NASA maintain this important role.

The NASA STI Program Office is operated by Langley Research Center, the Lead Center for NASA's scientific and technical information. The NASA STI Program Office provides access to the NASA STI Database, the largest collection of aeronautical and space science STI in the world. The Program Office is also NASA's institutional mechanism for disseminating the results of its research and development activities. These results are published by NASA in the NASA STI Report Series, which includes the following report types:

- $\quad$ TECHNICAL PUBLICATION. Reports of completed research or a major significant phase of research that present the results of NASA programs and include extensive data or theoretical analysis. Includes compilations of significant scientific and technical data and information deemed to be of continuing reference value. NASA's counterpart of peerreviewed formal professional papers but has less stringent limitations on manuscript length and extent of graphic presentations.

- TECHNICAL MEMORANDUM. Scientific and technical findings that are preliminary or of specialized interest, e.g., quick release reports, working papers, and bibliographies that contain minimal annotation. Does not contain extensive analysis.

- CONTRACTOR REPORT. Scientific and technical findings by NASA-sponsored contractors and grantees.
- CONFERENCE PUBLICATION. Collected papers from scientific and technical conferences, symposia, seminars, or other meetings sponsored or cosponsored by NASA.

- SPECIAL PUBLICATION. Scientific, technical, or historical information from NASA programs, projects, and missions, often concerned with subjects having substantial public interest.

- TECHNICAL TRANSLATION. Englishlanguage translations of foreign scientific and technical material pertinent to NASA's mission.

Specialized services that complement the STI Program Office's diverse offerings include creating custom thesauri, building customized databases, organizing and publishing research results ... even providing videos.

For more information about the NASA STI Program Office, see the following:

- Access the NASA STI Program Home Page at http://www.sti.nasa.gov

- E-mail your question via the Internet to help@sti.nasa.gov

- Fax your question to the NASA Access Help Desk at 301-621-0134

- Telephone the NASA Access Help Desk at 301-621-0390

- Write to:

NASA Access Help Desk

NASA Center for AeroSpace Information 7121 Standard Drive

Hanover, MD 21076 
NASA/TM-2005-213895

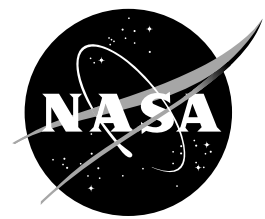

\section{Description of the Prometheus Program Alternator/Thruster Integration Laboratory (ATIL)}

Anastacio N. Baez, Arthur G. Birchenough, and Ramon C. Lebron-Velilla Glenn Research Center, Cleveland, Ohio

Marcelo C. Gonzalez

Cleveland State University, Cleveland, Ohio

Prepared for the

Third International Energy Conversion Engineering Conference sponsored by the American Institute of Aeronautics and Astronautics San Francisco, California, August 15-18, 2005

National Aeronautics and Space Administration

Glenn Research Center 
Trade names or manufacturers' names are used in this report for identification only. This usage does not constitute an official endorsement, either expressed or implied, by the National Aeronautics and Space Administration.

Available from

NASA Center for Aerospace Information 7121 Standard Drive

Hanover, MD 21076
National Technical Information Service 5285 Port Royal Road Springfield, VA 22100

Available electronically at http:/ /gltrs.grc.nasa.gov 


\title{
Description of the Prometheus Program Alternator/Thruster Integration Laboratory (ATIL)
}

\author{
Anastacio N. Baez, Arthur G. Birchenough, and Ramon C. Lebron-Velilla \\ National Aeronautics and Space Administration \\ Glenn Research Center \\ Cleveland, Ohio 44135 \\ Marcelo C. Gonzalez \\ Cleveland State University \\ Cleveland, Ohio 44115
}

\begin{abstract}
I. Abstract
The Project Prometheus Alternator Electric Thruster Integration Laboratory's (ATIL) primary two objectives are to obtain test data to influence the power conversion and electric propulsion systems design, and to assist in developing the primary power quality specifications prior to system Preliminary Design Review (PDR). ATIL is being developed in stages or configurations of increasing fidelity and complexity in order to support the various phases of the Prometheus program. ATIL provides a timely insight of the electrical interactions between a representative Permanent Magnet Generator, its associated control schemes, realistic electric system loads, and an operating electric propulsion thruster. The ATIL main elements are an electrically driven $100 \mathrm{kWe}$ Alternator Test Unit (ATU), an alternator controller using parasitic loads, and a thruster Power Processing Unit (PPU) breadboard. This paper describes the ATIL components, its development approach, preliminary integration test results, and current status.
\end{abstract}

\section{Introduction}

The NASA Vision for Space Exploration includes the development of innovative technologies, knowledge and infrastructure both to explore the solar system for scientific purposes and to support human exploration. As part of NASA's Space Exploration Program, Project Prometheus was created to develop technology and conduct studies in the areas of nuclear power and electric propulsion for the peaceful exploration of the solar system. It is anticipated that nuclear electric power (NEP) will provide the opportunity for much greater energy availability for spacecraft propulsion and electrical power for payload and communications. An integrated Prometheus Project team consisting of JPL, the supporting NASA Centers, the Department of Energy's Naval Reactors Prime Contractor Team (NRPCT), and Northrop Grumman Space Technology (NGST) were co-designing the Prometheus 1 Deep Space Vehicle (spacecraft module and reactor module).

NASA Glenn has extensive experience with Dynamic Power Systems and Electric Thrusters dating back to the 1960s. NASA GRC developed the NASA Solar Electric Propulsion Technology Application Readiness (NSTAR) primary propulsion ion thruster: the first ion thruster flown on a deep space science mission (Deep Space 1). GRC has also successfully demonstrated operation of a $2 \mathrm{~kW}$ Brayton Rotating Unit, associated power control and distribution, with an Engineering Model (EM) of the NSTAR gridded ion thruster (ref. 1).

Glenn Research Center is playing a major role in the development of the dynamic power conversion, power management and distribution, heat rejection and electric propulsion for Project Prometheus. In order to support the NASA Glenn Prometheus Project role, a flexible experimental facility to study endto-end EP electrical power system is under development. The Alternator Thruster Integration Laboratory (ATIL) includes a representative alternator and associated controller, power distribution hardware, and a representative Power Processing Unit (PPU) and electric thruster. In addition, GRC is responsible for the 
development (and validation by test) of analytical models for performance and lifetime prediction of the power conversion, management, and distribution system. The two primary objectives of the laboratory are to obtain test data to influence the power conversion and electric propulsion design and to assist in developing the primary power quality specifications (ref. 2) prior to system Preliminary Design Review (PDR). ATIL provides a timely insight of the electrical interactions between a representative Permanent Magnet Generator, its associated control schemes, realistic electric system loads, and an operating electric propulsion thruster.

\section{Test Facility Description}

The Alternator Electric Thruster Integration Laboratory (ATIL) is being developed in stages or configurations of increasing fidelity and complexity in order to support the various phases of the Prometheus program. A block diagram of the ATIL final configuration is shown in figure 1 and figure 2 shows a picture of the ATIL facility at NASA GRC. The ATIL main elements include an electrically driven $100 \mathrm{kWe}$ Alternator Test Unit (ATU), an alternator controller using parasitic loads, AC power distribution hardware, and a thruster Power Processing Unit (PPU) simulator. These elements have been developed using breadboard type hardware and/or simulated components. The ATIL initial configuration under development uses readily available off-the-shelf components. During the initial stage of ATIL a commercial AC power supply will be used to verify proper operation of the power distribution hardware, the alternator controller hardware, load simulators, and the facility control and data acquisition system. The power supply is capable of providing $90 \mathrm{KVA}$ of three-phase AC power at variable frequencies up to $2000 \mathrm{~Hz}$ and output voltage up to $528 \mathrm{VAC}$ line to line. External circuitry has been added to the power supply to simulate the output impedance of a representative PMG. The power supply will be replaced by the Alternator Test Unit in early 2006.

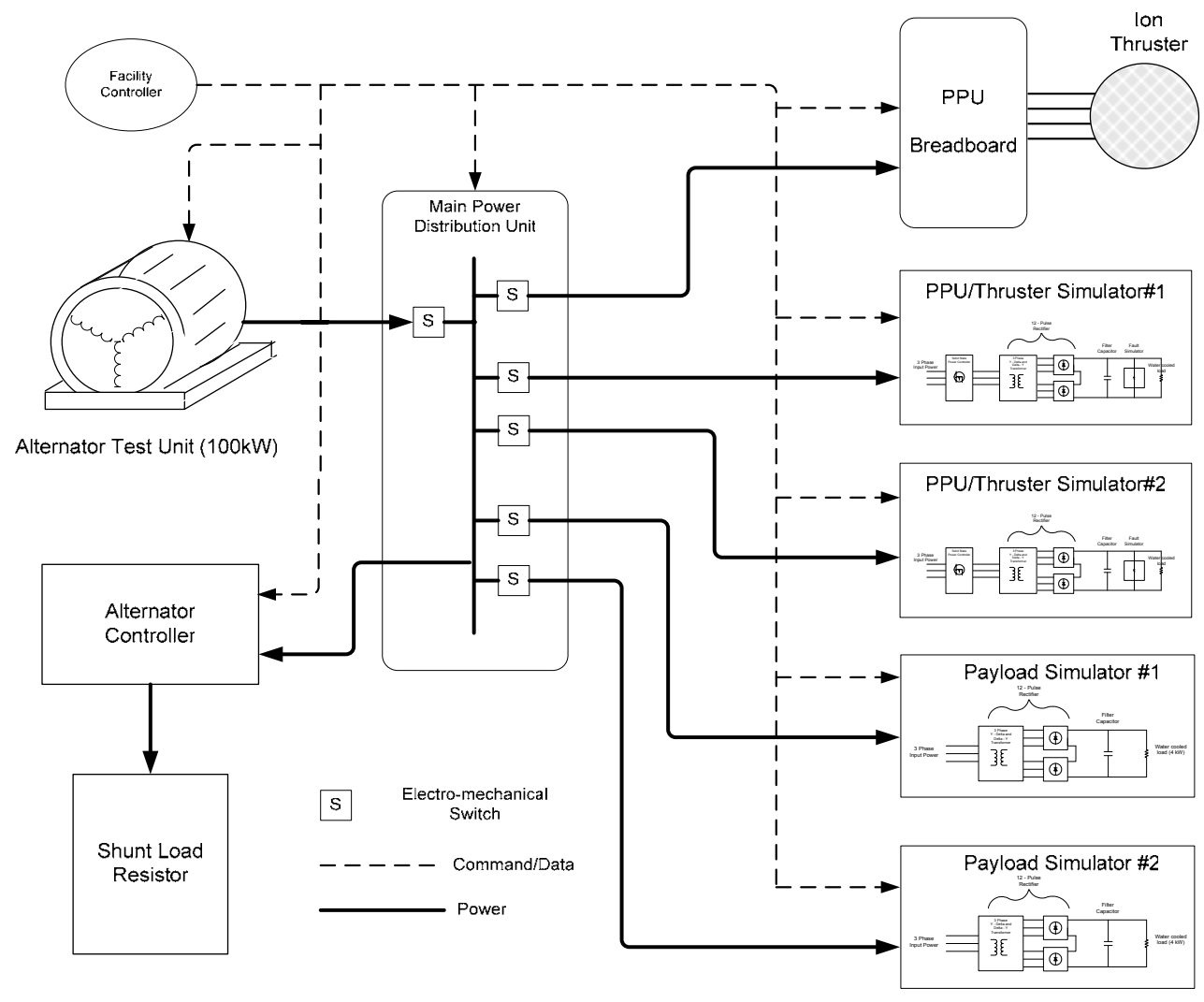

Figure 1.-ATIL Block Diagram. 


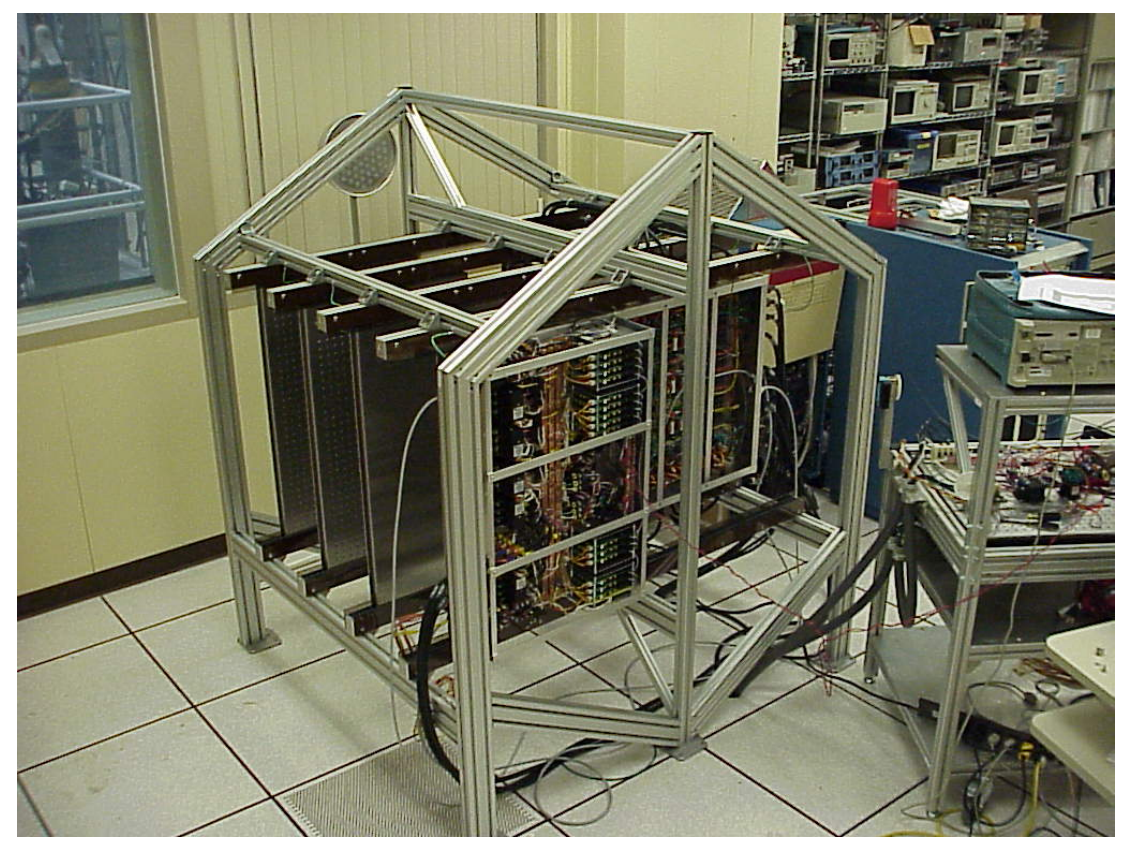

Figure 2.-ATIL Facility at NASA Glenn Research Center.

\section{A. Alternator Test Unit}

The Alternator Test Unit (ATU) is an electrically driven Permanent Magnet Generator that is being developed by Hamilton/Sundstrand for NASA. The output of the ATU is a sinusoidal $2250 \mathrm{~Hz}$ waveform rated at $100 \mathrm{kWe}, 440 \mathrm{~V}$ line to line. The ATU requires three-phase $480 \mathrm{Vac}, 60 \mathrm{~Hz}$ input power. The prime mover for the generator is a permanent magnet (Samarium Cobalt) 2-pole motor driven by a variable voltage and frequency inverter. The motor drive is capable of simulating Brayton Engine speed/torque characteristics in the generating mode, and can simulate the bearing drag and turbine compressor windage losses to simulate the motor starting mode. These simulation parameters can be modified by programming the motor controller algorithms. The ATU is also capable of operating in both torque and speed control modes. The motor will deliver $130 \mathrm{~kW}$ at 45,000-rpm continuously to the PMG. A cut-out diagram of the ATU is shown in figure 3.

An oil lubrication and cooling system is included in the ATU assembly. Oil jets are used to lubricate and cool each bearing and to cool the ends turns of the motor and alternator. Additionally, oil passages are used to cool the rotor and stator. The oil system is cooled using a heat exchanger attached to a facility water cooling system. The facility water loop also provides motor drive electronics cooling.

The alternator is a Permanent Magnet Generator (PMG), six pole, oil cooled, rated for a $100 \mathrm{~kW}$ output at $440 \mathrm{~V} \mathrm{AC}$ line to line, three-phase at a nominal power factor of 0.85 . The frequency is $2250 \mathrm{~Hz}$. The PMG rotor uses common Samarium Cobalt magnets in a Halbach array (ref. 3). The alternator design is representative of the Prometheus flight concept with similar power ratings $(100 \mathrm{~kW})$, similar rotor and stator construction, inertia and impedance, and similar operating rpm and frequency. The prime mover motor and PMG are in line coupled with a stiff spline coupling.

The prime mover, the PMG, the lubrication system, the system controller and motor drive electronics, and the input power conditioning hardware are all enclosed in a stand alone sound insulating cart. The ATU is being constructed to be used in a laboratory environment and is mounted on casters for ease of operation and handling. The control of the ATU is through a remotely located computer interface. The ATU system provides fault detection and management capability to protect against injury to a user or damage to the ATU itself. 


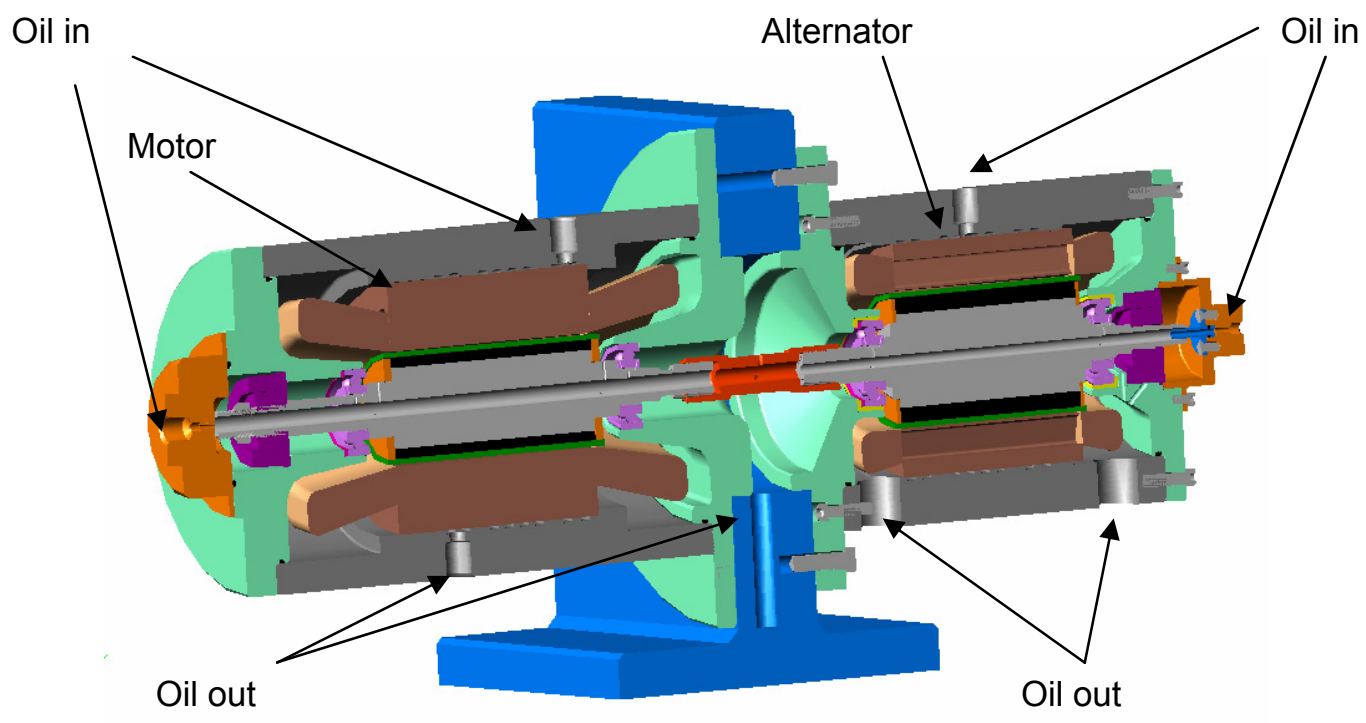

Figure 3.--Alternator Test Unit.

\section{B. Alternator Controller and Shunt Load Resistor (SLR)}

The alternator control function is based on applying a shunt or parasitic load to the alternator output in order to maintain a total load to the machine as required causing the machine to operate at the desired output voltage and/or speed. The alternator controller consists of two main circuits, the power circuits including the parasitic load elements, and the sensing circuits and feedback control loops sending the control signals to the power circuits.

Figure 4 contains a functional block diagram of the alternator controller. The power circuit uses a Wye-Delta transformer in combination with direct rectification of the power bus to effect a 12 pulse rectification of the bus power. The parasitic load resistor is connected across the rectified output, in series with a PWM FET switch, through an EMI filter to reduce noise radiated off the parasitic load. In the actual implementation two such resistor/EMI filter/PWM switch segments are connected in series to reduce the voltage requirement of the PWM switch. Additionally, there are 12 such circuits, each having a separate transformer-rectifier-parasitic load and PWM switch, in parallel to share the power and provide redundancy. The PWM switches are controlled by six-phase staggered signals to reduce waveform distortion.

The sensing and control circuits use a three-phase true root mean square voltage sensing, alternator speed sensing, and load current sensing as inputs. The basic control loop compares the sensed bus voltage to a reference, and uses a proportional plus integral control function to generate a command to the PWM modulator. Feed forward compensation for load current sensing is used to speed up the loop response. Additionally, alternator speed is sensed, and the error from the desired speed is used as a trim signal to change the voltage command slightly to run in a constant speed mode if desired. The PWM modulator generates 6 different PWM signals, equal width but phase shifted equally over a half the period of the alternator frequency to reduce waveform distortion by providing a more steady loading of the alternator.

\section{Main Power Distribution Unit (MPDU)}

The Main Power Distribution Unit contains the electrical switches and associated electronics to manage and distribute power from the generating power source to the user's loads and to the alternator controller. The unit's design accommodates dual power feeds to the main payloads and/or critical electrical loads. Figure 5 contains a functional block diagram of the MPDU and figure 6 shows a picture of this unit. 


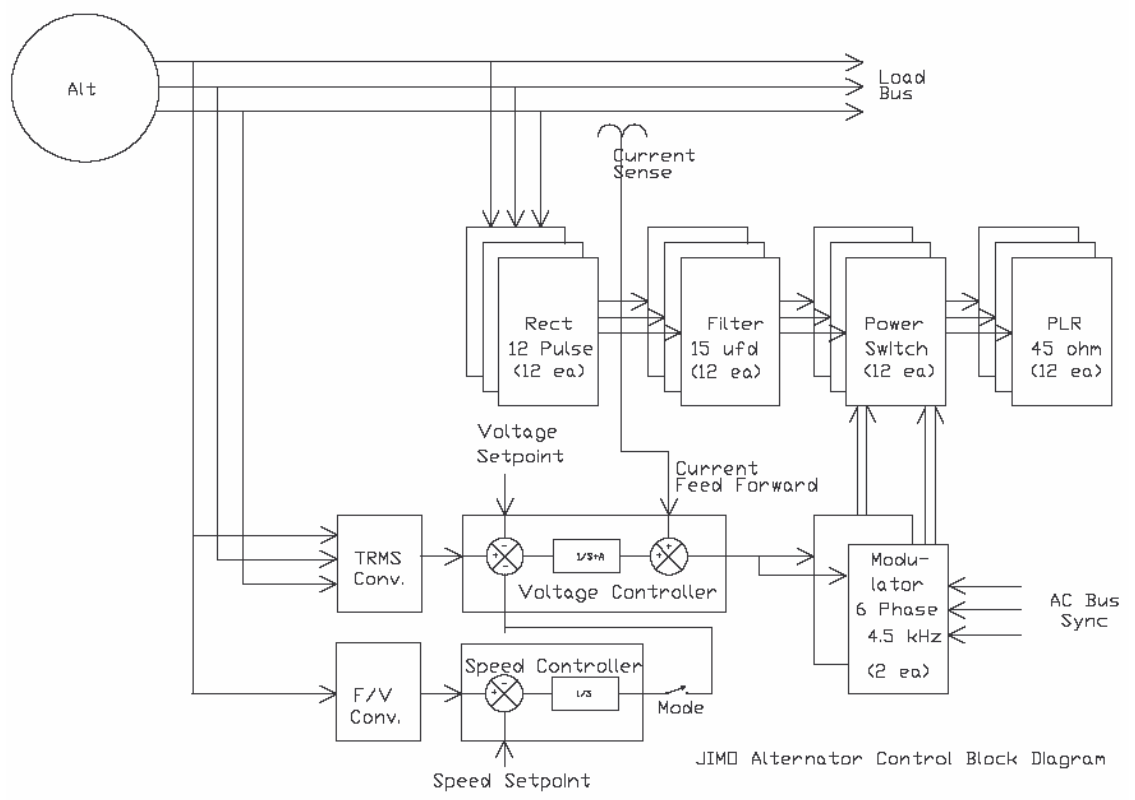

Figure 4.-ATIL Alternator Controller Block Diagram.

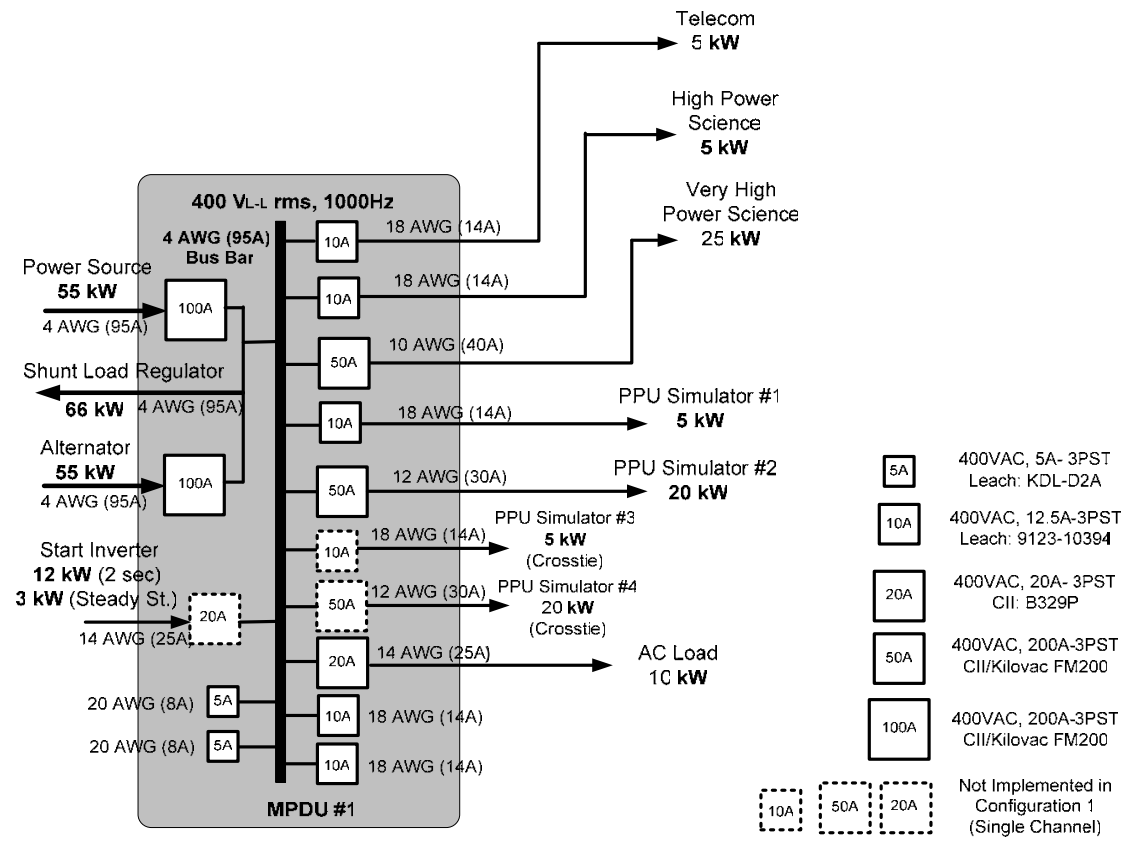

Figure 5.-ATIL Main Power Distribution Unit Block Diagram. 


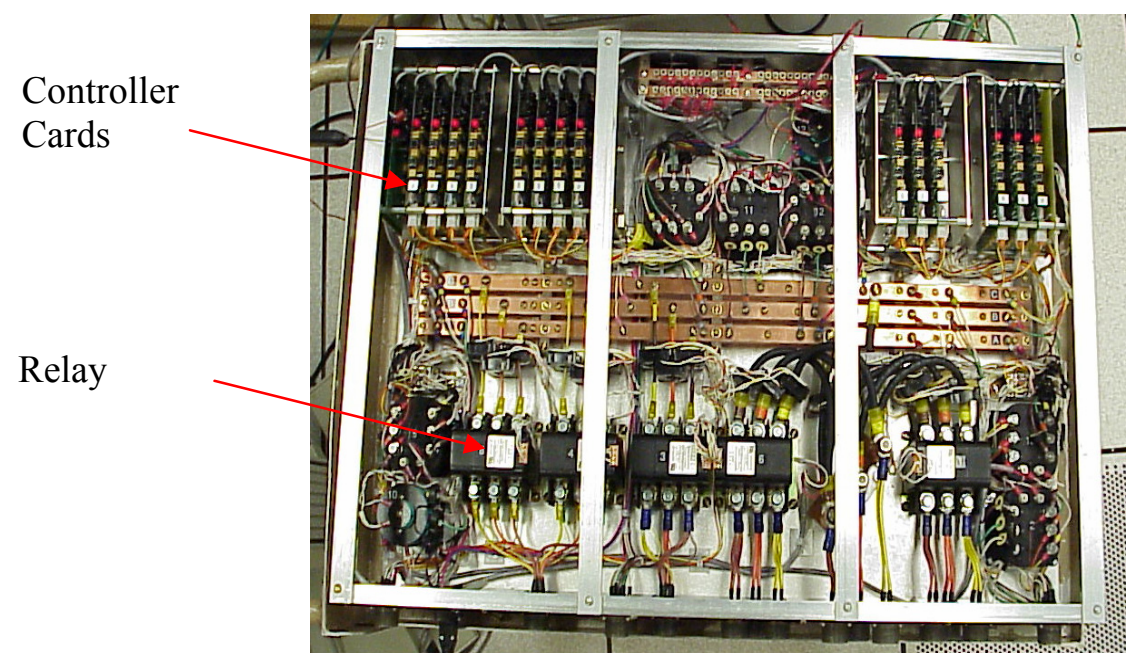

Figure 6.-Main Power Distribution Unit.

The MPDU is sized to distribute $100 \mathrm{~kW}$ of three-phase AC power at $440 \mathrm{~V}$ line to line (rms), $2250 \mathrm{~Hz}$. The electrical switches are 3-pole single throw electromechanical relays that are de-rated to operate at $440 \mathrm{~V}$ line to line (rms) at a frequency of $2250 \mathrm{~Hz}$. It should be noted that these relays are intended to be used with $400 \mathrm{~Hz}$ power distribution systems and manufacturers do not provide de-rating data on frequency. One secondary objective of the ATIL project is to validate the operation of these commercial off the shelf (COTS) relays in a mid-frequency (1500 to $2250 \mathrm{~Hz}$ ) power system application. There are four types of relays in the MPDU with current ratings of 100A, 20A, 10A, and 5A. Each of the MPDU relays has an associated custom built micro-controller circuit card assembly (CCA) that provides digital and analog data handling and control. The CCA controller is an industry standard 8051 microcontroller and contains the logic to implement current and voltage sensing as well as analog circuitry for $\mathrm{ON} / \mathrm{OFF}$ control and over-current protection. The over-current protection strategy is as follows: Instantaneous trip for currents 2 p.u. and above; and I (ref. 2) T (integrator) for currents higher than 1 p.u. but lower than 2 p.u. Both the over-current trip set-point (1 p.u. value) and instantaneous trip set-point (2 p.u. value) for each MPDU relay is adjustable. This feature will provide the flexibility to use the MPDU relays to feed and protect loads that require currents that are lower than the relay's nominal rating. A second type of CCA provides a single point data communication port between the MPDU and the main facility controller as well as senses the bus frequency and measure four temperature channels. The MPDU is air cooled and all its components are mounted on a common aluminum base plate.

\section{System Loads}

Project Prometheus was created to develop technology and conduct advanced studies in the areas of nuclear power and electric propulsion. A major challenge and principal area of technology development is the study of the interactions between the power generating source and large system loads like the electric propulsion thrusters and the high power scientific instruments. The ATIL project addresses these areas with the use of a combination of realistic electrical loads like the PPU/EP thruster breadboard and simulated loads. Figure 7 shows a functional block diagram of the PPU transformer-rectifier Load Simulator. These high power loads are powered directly from the main distributions bus with a $440 \mathrm{~V}$ line to line (rms) three-phase, $2250 \mathrm{~Hz}$ waveform. In order to process AC power, these loads will implement a three-phase Transformer-Rectifier that will change the AC voltage to the required voltage level and will then use a rectifier and filter to provide DC to the load. The rectifiers will be implemented as 12 pulse transformer rectifiers. The advantage of 12 pulse over 6 pulse rectifiers is a reduced bus voltage ripple, high power factor, and reduced harmonics in the AC bus. For loads that require multiple secondary 


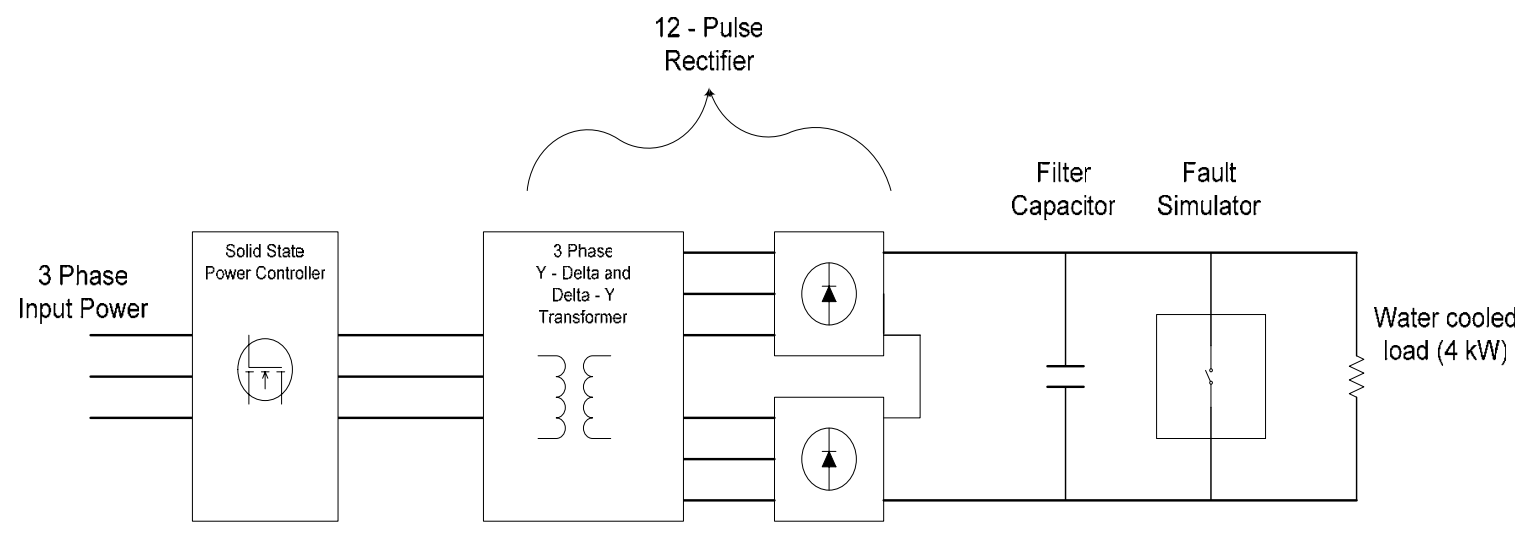

Figure 7.-_PPU Load Simulator Block Diagram.

windings to achieve high voltages, such as the Power Processing Units for electric propulsion, the 12 pulse transformer rectifier can be implemented by connecting some of the secondary windings in wye configuration, and the other secondary windings in delta configuration. This will provide the 30 degrees phase shift that is necessary for the 12 pulse rectification. This required phase shifting can also be implemented by means of a "Star Transformer". A "Star Transformer" is a three phase transformer that contains additional windings that provide series voltages that are out of phase with the phase (or line to line) voltages to produce a phase-angle-regulating transformer. The required phase shift is then proportional to the magnitude of the added series voltages from the additional windings.

In the Prometheus ATIL, it is important to represent the electrical behavior (rectification, power factor, harmonics, etc.) of high power transformer rectifier loads such as the PPU Simulator, High Power Science and Telecommunications. Therefore, each of these loads will be implemented with its own Transformer Rectifier Unit at the required power level and a resistive load bank. However, the output voltages for the transformer rectifier units in ATIL, may be different form the voltages that the actual loads will require. For practical purposes, the output voltage of the transformer rectifier units will be selected at a voltage value that is suitable and compatible with the Power Systems Facility resistive load bank equipment. In addition to the TRF, the PPU Simulator incorporates a solid state power controller and a fault simulator to represent the actual thruster recycles. These load simulators are modular and based on a $4 \mathrm{~kW}$ block or module.

\section{E. Facility Data Acquisition and Control (FDAC)}

The main functions of the Facility Data Acquisition and Control (FDAC) system are the collection of performance data from the various elements of the ATIL, execution of control algorithms, and derivation of the necessary control signals. Figure 8 shows a block diagram of the FDAC. The FDAC system consists of a commercial off-the-shelf computer and associated peripherals (e.g., Controller Area Network (CAN) Card, LonWorks Card, and USB-IEEE-488 Adapter/Expander) to meet software and control requirements of the ATIL.

The power control algorithms include: system initialization and start-up, operator command execution, system fault protection, and system shut-down. The ATIL performance data will be collected approximately every half a second to one second. As portrayed in figure 8, the FDAC system collects data from and issues commands to the various elements of the ATIL via various data bus interfaces. The MPDU and the Alternator Controller telemetry is via a CAN data bus (refs. 4 and 5) interface programmed to communicate at $500 \mathrm{kbps}$, although it is capable of communicating at $1 \mathrm{Mbps}$ at a 40 meters. Within the MPDU, digital and analog data handling and control between the single-point data communication CCA port and the relay CCAs is accomplished with a System Management Bus (refs. 6 and 7) (SMBus), which is I (ref. 2) C compatible, running at $100 \mathrm{kbps}$. The ATU will communicate with 


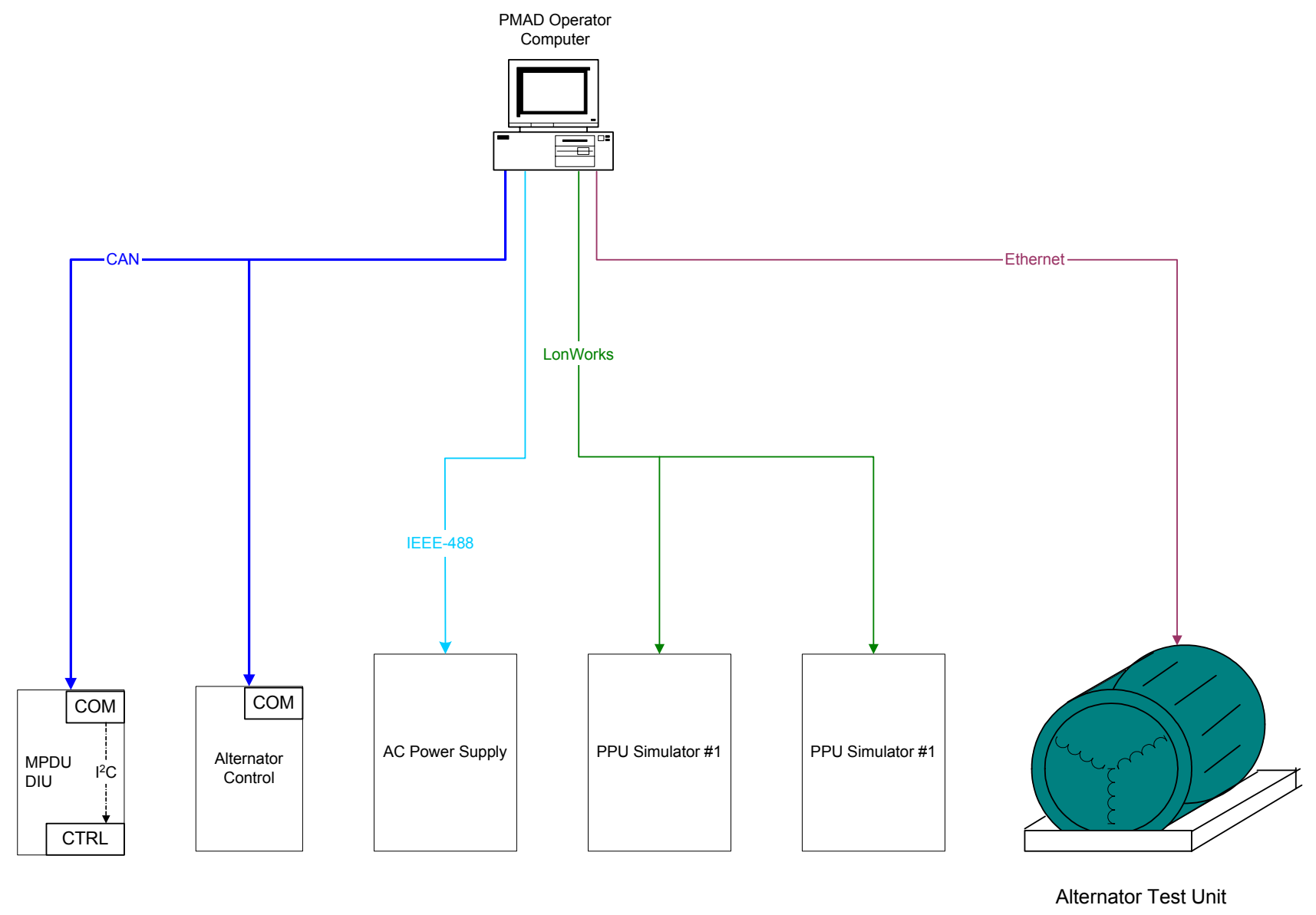

Figure 8.-Control and Data Acquisition System Block Diagram.

the FDAC via an Ethernet data bus and communication with the PPU Load Simulators, the Safety System, and the $28 \mathrm{~V}$ housekeeping Supply is through a LonWorks data interface. Communication with the AC Power Supply is accomplished via an IEEE-488 bus.

\section{Testing}

A series of tests will be conducted to verify end to end operation in the ATIL facility. Initially individual component performance verification testing will be conducted to characterize each major element of ATIL but the emphasis in this test facility will be the interactions between elements and system level performance. The series of tests include testing for normal operation and abnormal or out limits conditions, particularly the transients associated with the thruster operation, and the effect of transient conditions on the alternator, including the inductance of the long power cable between the alternator and the MPDU (see fig. 1). Tests will be conducted specifically to anchor the development of Power Quality Specifications. Among these tests are: steady state operation at various power levels, load transients, system start up, fault transients and recovery, waveform distortion and conducted EMI.

\section{A. Preliminary Test Results}

Figure 9 shows initial integration test results of the 90 KVA three-phase power supply with the Main Power Distribution Unit (MPDU) and the 12 pulse transformer rectifier loads. Three air core inductors were connected in series with each phase of the power supply to emulate the electrical source impedance 


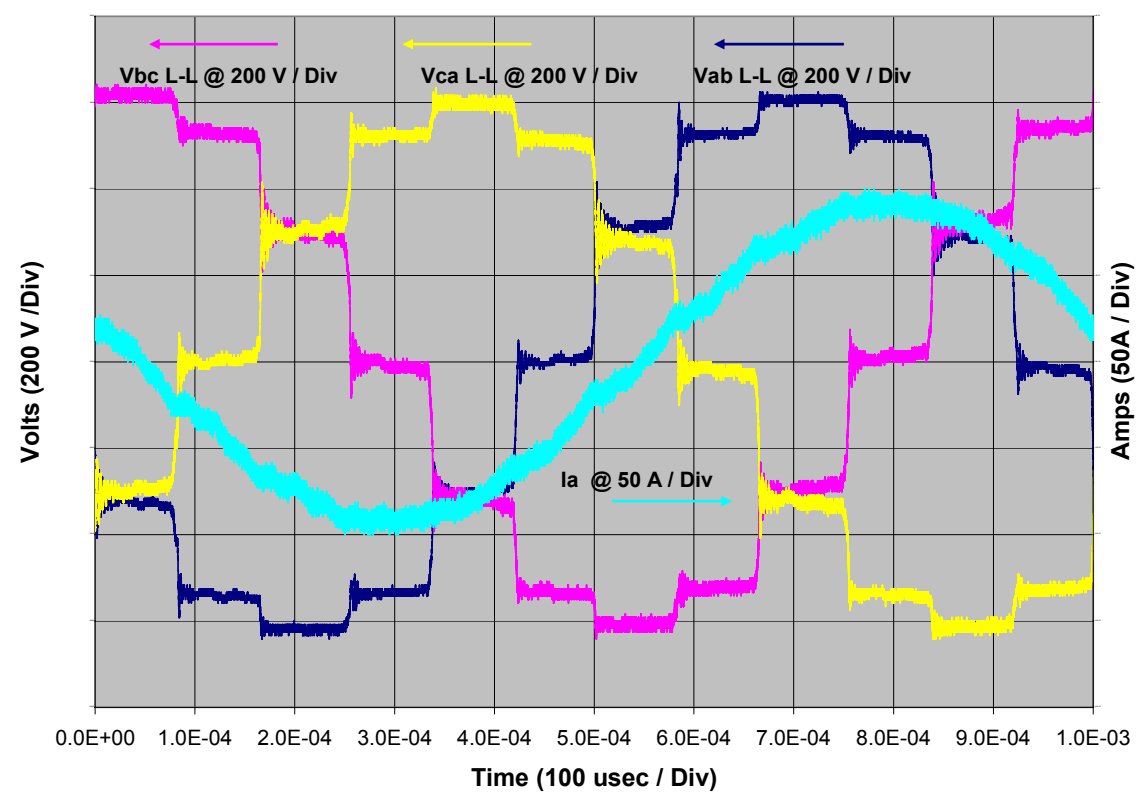

Figure 9.- Line to Line Voltages and Phase A Current in the MPDU

Main Distribution Bus with $48 \mathrm{~kW}$ on 12 Pulse Transformer

Rectifier Loads (200 V/Div and 50 A/Div).

of the ATU. This test was run with a line to line (rms) source voltage of 440 Vac, at a frequency of $1000 \mathrm{~Hz}$, with a total transformer rectifier load of $48 \mathrm{~kW}$. The voltage waveforms were taken at the MPDU Distribution Bus and they show the characteristic 12 step sine wave form produced by the transformer rectifier loads. The Phase A current shows a smooth sine wave shape due to the combination of the series air core inductance and the inductance of the long cable that connects the power source to the MPDU (see fig. 1). The inductance of this air core is 130 micro-henries and the cable inductance measured from the air core to the MPDU Input terminals is 10 micro-henries.

\section{Conclusion}

Project Prometheus was created to develop technology and conduct studies in the areas of nuclear power and electric propulsion in order to develop a nuclear powered spacecraft. The Alternator Thruster Integration Laboratory (ATIL) provides the Prometheus project a unique and flexible experimental facility to study end-to-end electrical power system, including a representative alternator and associated controller, and an Electric Propulsion Power Processing Unit. ATIL provides risk reduction and benefits to the project design effort prior to PDR (data available in 2006). ATIL provides experimental data to anchor the development of primary power quality specification. A major challenge and principal area of technology development is the study of the interactions between the power generating source and large system loads like the electric propulsion thrusters and the high power scientific instruments. The ATIL project addresses these areas with the use of a combination of realistic electrical loads like the PPU/EP thruster breadboard and simulated loads. ATIL's initial capability end to end (source to loads) system integration and tests is scheduled to begin in June 2005. 


\section{References}

1. Hervol, D., Mason, L., Birchenough, A. and Pinero, L. "Experimental Investigations from the Operation of a 2 kW Brayton Power Conversion Unit and a Xenon Ion Thruster," NASA/TM-2004212960, 2004.

2. JIMO Power Quality Specification, Unpublished DRAFT, NASA Advanced Electrical Systems Branch, March 4, 2004.

3. Halbach array DC motor/generator, United States Patent 5705902, Issued on January 6, 1998

4. Bosch, R., "CAN Specification," Version 2.0, Stuttgard, 1991.

5. Bosch, R., "C_CAN User's Manual," Revision 1.2, June 6, 2000.

6. SBS Implementers Forum, "System Management Bus Specification," Version 2.0, August 3, 2000.

7. Philips Semiconductor, "The I (ref. 2) C Bus and How to use it (including specification)," April, 1995. 
Public reporting burden for this collection of information is estimated to average 1 hour per response, including the time for reviewing instructions, searching existing data sources, gathering and maintaining the data needed, and completing and reviewing the collection of information. Send comments regarding this burden estimate or any other aspect of this collection of information, including suggestions for reducing this burden, to Washington Headquarters Services, Directorate for Information Operations and Reports, 1215 Jefferson Davis Highway, Suite 1204, Arlington, VA 22202-4302, and to the Office of Management and Budget, Paperwork Reduction Project (0704-0188), Washington, DC 20503.

\begin{tabular}{|l|l|l}
\hline 1. AGENCY USE ONLY (Leave blank) & $\begin{array}{c}\text { 2. REPORT DATE } \\
\text { November } 2005\end{array}$ & $\begin{array}{r}\text { 3. REPORT TYPE AND DATES COVERED } \\
\text { Technical Memorandum }\end{array}$
\end{tabular}

4. TITLE AND SUBTITLE 5. FUNDING NUMBERS

Description of the Prometheus Program Alternator/Thruster Integration Laboratory (ATIL)

6. AUTHOR(S)

WBS-22-973-80-10

Anastacio N. Baez, Arthur G. Birchenough, Ramon C. Lebron-Velilla, and Marcelo C. Gonzalez

7. PERFORMING ORGANIZATION NAME(S) AND ADDRESS(ES)

National Aeronautics and Space Administration

John H. Glenn Research Center at Lewis Field

Cleveland, Ohio 44135-3191
8. PERFORMING ORGANIZATION REPORT NUMBER

E-15266

\section{SPONSORING/MONITORING AGENCY NAME(S) AND ADDRESS(ES)}

National Aeronautics and Space Administration

Washington, DC 20546-0001
10. SPONSORING/MONITORING AGENCY REPORT NUMBER

NASA TM-2005-213895

AIAA-2005-5714

\section{SUPPLEMENTARY NOTES}

Prepared for the Third International Energy Conversion Engineering Conference sponsored by the American Institute of Aeronautics and Astronautics, San Francisco, California, August 15-18, 2005. Anastacio N. Baez, Arthur G. Birchenough, and Ramon C. Lebron-Velilla, NASA Glenn Research Center; and Marcelo C. Gonzalez, Cleveland State University, 2121 Euclid Avenue, Cleveland, Ohio 44115-2226. Responsible person, Ramon C. Lebron-Velilla, organization code RPE, 216-433-6482.

12a. DISTRIBUTION/AVAILABILITY STATEMENT

Unclassified - Unlimited

Subject Category: 33

Available electronically at http://gltrs.grc.nasa.gov

This publication is available from the NASA Center for AeroSpace Information, 301-621-0390.

\section{ABSTRACT (Maximum 200 words)}

The Project Prometheus Alternator Electric Thruster Integration Laboratory's (ATIL) primary two objectives are to obtain test data to influence the power conversion and electric propulsion systems design, and to assist in developing the primary power quality specifications prior to system Preliminary Design Review (PDR). ATIL is being developed in stages or configurations of increasing fidelity and complexity in order to support the various phases of the Prometheus program. ATIL provides a timely insight of the electrical interactions between a representative Permanent Magnet Generator, its associated control schemes, realistic electric system loads, and an operating electric propulsion thruster. The ATIL main elements are an electrically driven $100 \mathrm{kWe}$ Alternator Test Unit (ATU), an alternator controller using parasitic loads, and a thruster Power Processing Unit (PPU) breadboard. This paper describes the ATIL components, its development approach, preliminary integration test results, and current status.

\section{SUBJECT TERMS}

Electric circuits; Electric motors; Electrical power unit; Generators; Electrical relays; Transformers; Rectifiers; Electrical power systems facilities

\begin{tabular}{|c|c|c|}
\hline $\begin{array}{c}\text { 17. SECURITY CLASSIFICATION } \\
\text { OF REPORT } \\
\text { Unclassified }\end{array}$ & $\begin{array}{c}\text { 18. SECURITY CLASSIFICATION } \\
\text { OF THIS PAGE } \\
\text { Unclassified }\end{array}$ & $\begin{array}{c}\text { 19. SECURITY CLASSIFICATION } \\
\text { OF ABSTRACT } \\
\text { Unclassified }\end{array}$ \\
\hline
\end{tabular}



